\title{
Article \\ The Longitudinal Relationship between Internet Addiction and Depressive Symptoms in Adolescents: A Random-Intercept Cross-Lagged Panel Model
}

\author{
Xiaoyan $\mathrm{Yi}^{1}$ and Guangming $\mathrm{Li}^{1,2,3,4, *}$ \\ 1 School of Psychology, South China Normal University, Guangzhou 510631, China; yxy2020@m.scnu.edu.cn \\ 2 Key Laboratory of Brain, Cognition and Education Sciences, Ministry of Education, \\ South China Normal University, Guangzhou 510631, China \\ 3 Center for Studies of Psychological Application, School of Psychology, South China Normal University, \\ Guangzhou 510631, China \\ 4 Guangdong Key Laboratory of Mental Health and Cognitive Science, South China Normal University, \\ Guangzhou 510631, China \\ * Correspondence: 20131157@m.scnu.edu.cn
}

\section{check for}

updates

Citation: Yi, X.; Li, G. The Longitudinal Relationship between Internet Addiction and Depressive Symptoms in Adolescents: A Random-Intercept Cross-Lagged Panel Model. Int. J. Environ. Res. Public Health 2021, 18, 12869. https://doi.org/10.3390/ ijerph182412869

Academic Editors: Gergely Fehér and Gergely Darnai

Received: 30 October 2021

Accepted: 30 November 2021

Published: 7 December 2021

Publisher's Note: MDPI stays neutral with regard to jurisdictional claims in published maps and institutional affiliations.

Copyright: (C) 2021 by the authors Licensee MDPI, Basel, Switzerland. This article is an open access article distributed under the terms and conditions of the Creative Commons Attribution (CC BY) license (https:/ / creativecommons.org/licenses/by/ $4.0 /)$.

\begin{abstract}
Internet addiction and depressive symptoms are extremely common problems among teenagers, and the coping strategy has been proved to be closely related to internet addiction and depressive symptoms. Based on three waves of data from a sample of Chinese middle-school students $\left(N=1545, M_{\text {age }}=14.88\right.$ years old, $S D=1.81 ; 55.00 \%$ females $)$, this study examines the longitudinal relationship between internet addiction and depressive symptoms among adolescents ultilizing the random-intercept cross-lagged panel model. Results revealed a unidirectional predictive effect of depressive symptoms at $\mathrm{T}_{2}$ on internet addiction at $\mathrm{T}_{3}$, but not vice versa, the effect was more significant in the male group. Positive coping strategies had a significant negative predictive effect on the random intercept of internet addiction and depressive symptoms, while negative coping style had a significant positive predictive effect on the random intercept of internet addiction and depressive symptoms. Effective identification and intervention of depressive symptoms may be beneficial to the intervention and prevention for internet addiction, and we should pay attention to the cultivation of middle school students' positive coping strategies.
\end{abstract}

Keywords: internet addiction; depressive symptoms; middle school students; RI-CLPM

\section{Introduction}

Internet addiction and depressive symptoms are extremely common problems among teenagers today. The number of internet users in China had reached 1.01 billion, and youth aged 10-19 accounted for $12.3 \%$ of total internet users by June 2021 [1]. While the internet brings many conveniences to people's lives, it also has some negative effects. Among them, the problem of teenagers' internet addiction has attracted increasing attention from all walks of life. internet addiction (IA), also known as problematic internet use (PIU), is defined as an impulse-control disorder that does not involve intoxicants [2]. In 2020, the number of juvenile internet users in China was 183 million, and 19.6\% of them believed that they were psychologically dependent on the internet [3] (CNNIC, 2020). internet addiction can lead to obvious social, behavioral and health damage, such as loneliness and anxiety [4,5], which seriously affects the healthy growth of adolescents.

In addition to internet addiction, depression is also very common among adolescents. Related studies show that the incidence of depressive symptoms in middle school students in China is between 25.5-44\% [6]. Depression can affect children and adolescents' development, school performance, relationship with peers and family, and even lead to suicide [7]. 
Coping strategy, as a relatively stable cognitive and behavioral style, has been proved to be closely related to internet addiction and depressive symptoms [8,9]. Exploring how coping strategy can affect internet addiction and depressive symptoms in one model will be helpful to understanding the relationship between the three variables in more depth and is of great significance for identifying potential risk groups.

\subsection{Relationship between Internet Addiction and Depressive Symptoms}

There are three hypotheses explaining the relationship between IA and depressive symptoms.

Kraut et al. proposed the social displacement hypothesis, believing that using the internet adversely affects social involvement and psychological well-being [10]. Addiction to online social interaction reduces the time teenagers spend interacting with friends and family in real life, which may lead to maladjustment and the emergence of negative emotions such as depression. Bryant and Zillmann proposed the mood enhancement hypothesis, suggested that individuals use media based on their emotions, which means that they will selectively contact online content according to their emotions [11]. The internet provides adolescents with social support, a sense of accomplishment and controls, allowing them to escape from the real world where emotional difficulties occur into the virtual world. Adolescents with depressive symptoms were more prone to use the internet to ease their depression, and therefore they are more likely than their peers to be addictive to the internet [12]. Davis (2001) proposed a cognitive-behavioral model of pathological internet use (PIU), positing that PIU results from problematic cognitions coupled with behaviors that either intensify or maintain the maladaptive response. Psychopathology (e.g., depression) is a distal necessary cause of symptoms of PIU. Depressive individuals may hold more pessimistic perceptions of their social skills and prefer online communications, so they may spend an excessive amount of time on the internet to seek support and pleasure, which may increase their risk of becoming problematic internet users [13].

Many studies have found that relationships between internet addiction and depressive symptoms among adolescents. In cross-sectional studies, some suggest that internet addiction may be a risk factor for depression [10,14], while some other studies suggest that depression may be a risk factor for internet addiction $[12,15]$. Although there are several longitudinal research works on the longitudinal relationship between internet addiction and depressive symptoms, the results are inconsistent. Some studies believe that there is only a unidirectional prediction relationship between the two variables [16,17], and some that there is a bidirectional prediction relationship $[18,19]$.

Most of longitudinal studies employ the traditional cross-lagged panel model (CLPM), a model that explores causality among variables by predicting the extent to which an individual will deviate from the group mean at a previous time point by another variable at the next time point. The biggest limitation of this model is that it mixes within-person effects and between-person effects, making the causal relationship between variables unclear. Within-person effects focus on how the changes in one variable are associated with the changes in another variable over time within an individual; between-person effects focus on how the changes in one variable are associated with the changes in another variable over time between different individuals. When CLPM is used to explore the longitudinal relationship between internet addiction and depressive symptoms, it is assumed that each individual has the same baseline level of internet addiction and depressive symptoms, meaning that all individuals' scores fluctuate around the same baseline level (the group mean), and there is no stable individual differences. Obviously, this condition is hard to meet. Because of the baseline level of individual depressive symptoms, internet addiction is bound to show stable differences.

In order to capture the stability difference between individuals and separate the within-person effects and between-person effects, some scholars proposed the random intercept cross-lagged model (RI-CLPM) [20]. Therefore, the current study will also use 
this model to explore the longitudinal relationship between adolescent internet addiction and depressive symptoms.

\subsection{Gender Differences in Internet Addiction}

A lot of cross-sectional studies found that there is a gender difference in adolescent internet addiction, and males are more prone to internet addiction than females [21,22]. Yu et al. conducted 3-year longitudinal research on Hong Kong adolescents, and found that male adolescents were $40 \%$ more likely to become addicted to the internet than female adolescents [23]. Many reports point to gender differences in motivation for using the internet. Men tended to experience more addictive behaviors when playing games related to power, control or explore sexual fantasies online, while women were more likely to communicate with close, anonymous friends online to share their feelings and emotions [2]. Men and women use the internet as a result of different patterns of behavior and motivation: compared with women, men are more easily depressed, avoid emotional problems, so more inclined to use internet addiction to avoid depression, the internet is more likely to be for fun, and tend to be with friends on the internet, so depression in men is predicted from subsequent internet addiction. However, women are more inclined to search for information on the internet and prefer to surf the internet alone, which makes women more prone to internet addiction due to overuse of the internet [19].

\subsection{Gender Differences in Depressive Symptoms}

There is a lot of evidence that gender differences in depression occur in early adolescence $[24,25]$. Before puberty, boys had higher levels of depression than girls, but after puberty, the results were reversed [26]. Women generally show increasingly pronounced symptoms of depression than men, and the gender difference becomes more pronounced during adolescence [27]. During adolescence, women face earlier biological changes and are more influenced by the quality and stress of the social environment, so they are more prone to developing depressive symptoms [28].

Above all, there are gender differences in adolescent internet addiction and depressive symptoms, but few researchers studied gender differences in longitudinal relationships between adolescent internet addiction and depressive symptoms by separating the betweenperson and within-person effect, which therefore still needs further research.

\subsection{Coping Strategy and Internet Addiction, Depression}

Coping is the cognition and behavior that individuals use to evaluate or reduce stress caused by life events in order to relieve internal tension [29]. Coping style, also known as coping strategy or mechanism, refers to the cognitive and behavioral styles adopted by individuals in the face of setbacks and pressures. Coping strategies can be classified into positive coping strategies and negative coping strategies according to their impact on mental and physical health, the former is an positive, effective and adaptive coping strategies adopted by individuals; the latter is a negative, ineffective and maladaptive coping strategies adopted by individuals.

Numerous studies have pointed out that coping strategy is closely related to internet addiction [30]. Whang found that compared with potential internet addicts and noninternet addicts, internet addicts reported more that they played online games because they wanted to escape from reality [31].

Individuals who tend to use a positive coping strategy tend to use information on the internet to solve problems in real life, then internet use is "problem solving" oriented, they are not prone to suffer from internet addiction. Al-gamal et al. found that individuals who chose a problem-solving coping strategy had a lower level of internet addiction [8].

Many researchers have found that an individual's coping strategy can affect his or her mental health. In terms of coping with stressful situations, adolescents who adopt a negative coping strategy have more psychological problems than those who adopt a positive coping strategy [32,33]. While individuals use negative coping strategies their 
anxiety and depression levels also increase [9,34]; and the increase in depressive symptoms, anxiety and other mood problems is associated with a decrease in positive individual coping strategies [35].

In conclusion, coping strategies are closely related to internet addiction and depressive symptoms, but few studies have explored how coping strategies can affect internet addiction and depressive symptoms at between-person level, so it is necessary to investigate the influence of coping strategies on adolescent internet addiction and depressive symptoms at a between-person level so as to identify potential risk groups.

\section{Methods}

\subsection{Participants and Procedure}

Participants were teenagers ( $N=1545,55.00 \%$ females) aged between 12 and 18 $(M=14.88 ; S D=1.81)$ from three middle schools in southern urban China. After excluding the subjects who did not take part in the measurement twice, 1459 valid subjects were retained. The reasons for the loss of subjects were as follows: (1) absence on the test day. (2) The questions were filled in wrong or missed. Table 1 presents the demographic information of the subjects.

Table 1. Characteristics of participants.

\begin{tabular}{ccc}
\hline & $N$ & $\%$ \\
\hline Gender & 651 & \\
Male & 808 & 44.619 \\
Female & & 55.380 \\
\hline Only child & 820 & \\
yes & 639 & 56.202 \\
no & & 43.797 \\
\hline Age & 778 & \\
$11-15$ & 681 & 53.324 \\
$16-19$ & &
\end{tabular}

We randomly selected three middle schools in urban areas in southern China, and then randomly chose 17 classes from these three middle schools. Data were collected using paper/pencil tests in classrooms every three months for a total study span of six months. Each participant had a unique ID, and the same ID was used at all three waves. No participants changed classes or schools during these six months. The measurement sites were provided by the Academic Affairs Offices of the three middle schools. Researchers were trained before they administered the survey. Both schools and parents agreed the assessment, and this research was approved by the university research ethics board (Institutional Review Board).

\subsection{Measures}

\subsubsection{Internet Addiction}

The Chinese version of Young's Internet Addiction Test (IAT) (Young, 1998) [2] was used to measure internet addiction. IAT has 20 items, all of them rated on five-point scales, ranging from 1 (rarely) to 5 (always) and summed, the higher the total score, the more serious level of internet addiction. The Cronbach's alpha for those items were good $\left(\mathrm{T}_{1 \alpha}=0.909 ; \mathrm{T}_{2 \alpha}=0.917 ; \mathrm{T}_{3 \alpha}=0.932\right)$.

\subsubsection{Depressive Symptoms}

Depressive symptoms was assessed using Zung's self-rating depression scale (SDS) [36]. SDS had 20 items (e.g., "I feel down-hearted and blue."), all of them rated on five-point scales, ranging from 1 (a little of the time) to 5 (most of the time) and summed, the higher the total score, the more serious level of depressive symptoms. The Cronbach's alpha for those items were good $\left(\mathrm{T}_{1 \alpha}=0.795 ; \mathrm{T}_{2 \alpha}=0.827 ; \mathrm{T}_{3 \alpha}=0.850\right)$. 


\subsubsection{Coping Style}

Coping styles was measured in the first wave using the Chinese version of the Trait Coping Style Scale (TCSQ). It has 20 items, 10 of them used to measure negative coping (NC) while the other 10 used to measure positive coping (PC); all of items are rated on a five-point scale, ranging from 1 (never) to 5 (always). The higher the score for each dimension, the more likely participants are to adopt this coping style. The Cronbach's alpha for those items was good $\left(\mathrm{T}_{1 \alpha}=0.857\right)$.

\subsection{Statistical Analyses}

Statistical analyses were conducted using SPSS26.0 (IBM Corporation, Armonk, NY, USA) and Mplus 7.4 (MPLUS 7.4 is a data analysis and statistical software developed by MUTHEN \& MUTHEN located in Los Angeles, CA, USA). The evaluation of model fitting adopts the following indexes proposed by Kline: the chi-square statistic $\left(\chi^{2}\right)$, the root-mean-square error of approximation (RMSEA; acceptable $<0.08$, good $<0.05$ ), the standardized root-mean-square residual (SRMR; acceptable $<0.08$, good $<0.05$ ) and the comparative fit index (CFI; acceptable $>0.90$, good $>0.95$ ) [37].

Utilizing the RI-CLPM, we decomposed the within-person effects and between-person effects among associations between internet addiction (IA) and depressive symptoms. Next, we divided males and females into two groups and established the RI-CLPM, respectively, to examine gender differences in the relationship between internet addiction (IA) and depressive symptoms; we also included covariates (age and coping style) to investigate their effects on random intercepts of internet addiction and depressive symptoms.

\section{Results}

3.1. Descriptive Statistics, Correlations, and Prevalence of Internet Addiction (IA) and Depressive Symptoms

Descriptive statistics of all variables and prevalence of IA and depressive symptoms across waves are shown in Table 2.

Table 2. Prevalence of internet addiction (IA) and depressive symptoms.

\begin{tabular}{|c|c|c|c|}
\hline & First $\left(\mathrm{T}_{1}\right)$ & Second $\left(T_{2}\right)$ & Third $\left(T_{3}\right)$ \\
\hline \multicolumn{4}{|l|}{ IA } \\
\hline Mean (SD) & $33.60(11.91)$ & $32.01(10.82)$ & $29.72(10.48)$ \\
\hline \multicolumn{4}{|l|}{ IA $n(\%)$} \\
\hline$\leq 50$ & $155(10.62 \%)$ & $117(8.01 \%)$ & $79(5.41 \%)$ \\
\hline$\leq \overline{50}<80$ & $146(10.00 \%)$ & $114(7.81 \%)$ & $74(5.07 \%)$ \\
\hline $80 \leq$ & $9(0.62 \%)$ & $3(0.21 \%)$ & $5(0.34 \%)$ \\
\hline \multicolumn{4}{|c|}{ Depressive symptoms } \\
\hline Mean (SD) & $39.43(8.42)$ & $37.02(8.62)$ & $37.21(9.65)$ \\
\hline \multicolumn{4}{|c|}{ Depressive symptoms n (\%) } \\
\hline $41<$ & $615(42.15 \%)$ & $460(31.53 \%)$ & $540(37.01 \%)$ \\
\hline
\end{tabular}

The correlations between IA and depressive symptoms are shown in Table 3. A significant positive correlation was found between all variables.

\subsection{The Results of the Random Intercept Cross-Lagged Model (RI-CLPM)}

The RI-CLPM demonstrated a good fit to the data $\left(\chi^{2}=145.275 d f=13, p<0.001\right.$; $\mathrm{CFI}=0.961 ; \mathrm{TLI}=0.901 ; \mathrm{RMSEA}=0.084,90 \% \mathrm{CI}[0.072,0.096] ; \mathrm{SRMR}=0.063)$.

Figure 1 shows the results of the RI-CLPM among total sample. 
Table 3. Correlation coefficients among key variables.

\begin{tabular}{lccccccc}
\hline & Variable & $\begin{array}{c}\text { IA } \\
\mathbf{T}_{\mathbf{1}}\end{array}$ & $\begin{array}{c}\text { IA } \\
\mathbf{T}_{\mathbf{2}}\end{array}$ & $\begin{array}{c}\text { IA } \\
\mathbf{T}_{\mathbf{3}}\end{array}$ & $\begin{array}{c}\mathbf{D E P} \\
\mathbf{T}_{\mathbf{1}}\end{array}$ & $\begin{array}{c}\text { DEP } \\
\mathbf{T}_{\mathbf{2}}\end{array}$ & $\begin{array}{c}\text { DEP } \\
\mathbf{T}_{\mathbf{3}}\end{array}$ \\
\hline 1 & $\mathrm{IA} \mathrm{T}_{1}$ & 1 & & & & & \\
2 & $\mathrm{IA} \mathrm{T}_{2}$ & 0.56 & 1 & & & & \\
3 & $\mathrm{IA} \mathrm{T}_{3}$ & 0.57 & 0.58 & 1 & & & \\
4 & $\mathrm{DEP} \mathrm{T}_{1}$ & 0.24 & 0.19 & 0.2 & 1 & & \\
5 & $\mathrm{DEP} \mathrm{T}_{2}$ & 0.23 & 0.33 & 0.24 & 0.49 & 1 & 1 \\
6 & $\mathrm{DEP} \mathrm{T}_{3}$ & 0.20 & 0.21 & 0.22 & 0.44 & 0.51 & \\
\hline
\end{tabular}

All correlation coefficients were significant at $p<0.001$. IA: internet addiction; DEP: depressive symptoms.

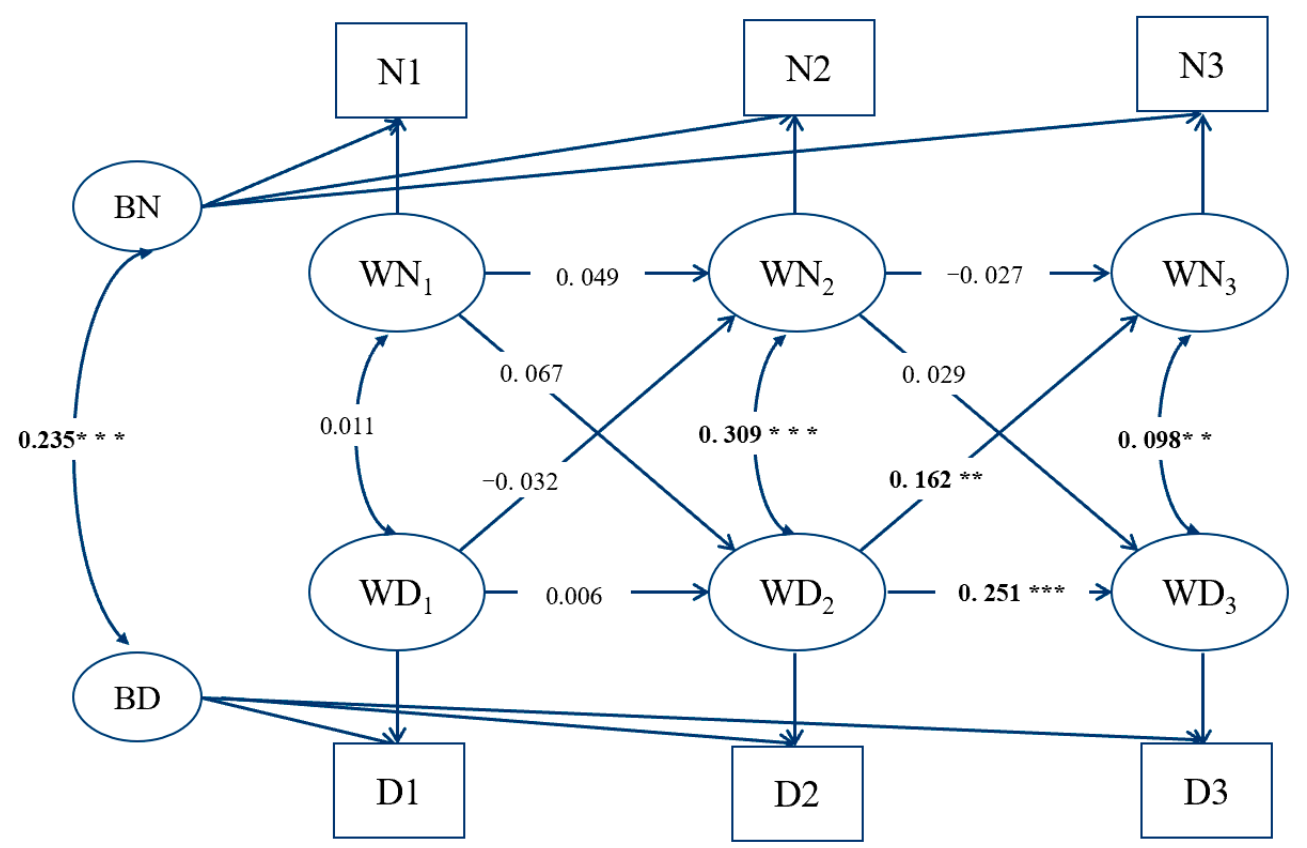

Figure 1. Random intercept cross-lagged model (RI-CLPM) of total sample. Notes. BN = intercept of internet addiction, $\mathrm{BD}=$ intercept of depressive symptoms, $\mathrm{WN}=$ the within-person fluctuations of internet addiction, $\mathrm{WD}=$ the within-person fluctuations of depressive symptoms, N1-N3 are total scores of internet addiction at wave 1-wave 3, D1-D3 are total scores of depressive symptoms at wave 1 -wave 3 ; $^{* *} p<0.01{ }^{* * *} p<0.001$.

Focusing on the cross-paths between two key variables, the coefficients for depressive symptoms at $\mathrm{T}_{2}(\mathrm{WD} 2)$ to IA at $\mathrm{T}_{3}(\mathrm{WN} 3)$ were significant $(\beta=0.162, p=0.003)$, indicating that depressive symptoms at $\mathrm{T}_{2}(\mathrm{WD} 2)$ predicted the increases in IA at $\mathrm{T}_{3}(\mathrm{WN} 3)$. The coefficients for depressive symptoms at $\mathrm{T}_{1}(\mathrm{WD} 1)$ to IA at $\mathrm{T}_{2}(\mathrm{WN} 2)$ were non-significant $(\beta=-0.032, p=0.470)$. Both the coefficients for IA at $\mathrm{T}_{1}(\mathrm{WN} 1)$ to depressive symptoms at $\mathrm{T}_{2}$ (WD2) $(\beta=0.067, p=0.146)$ and the coefficients for IA at $\mathrm{T}_{2}(\mathrm{WN} 2)$ to depressive symptoms (WD3) at $\mathrm{T}_{3}(\beta=0.029, p=0.448)$ were non-significant.

3.3. Gender Differences in the Relationship between Internet Addiction and Depressive Symptoms and the Effects of Covariates

The RI-CLPM for male group showed acceptable model fits, model fitting index are shown in Table 4, model diagram is shown in Figure 2.

Table 4. Model fitting index for male group.

\begin{tabular}{cccccc}
\hline CFI & TLI & SRMR & RMSEA & $\chi^{2}$ & $p$ \\
\hline 0.93 & 0.82 & 0.08 & 0.10 & 107.18 & 0.00 \\
\hline
\end{tabular}




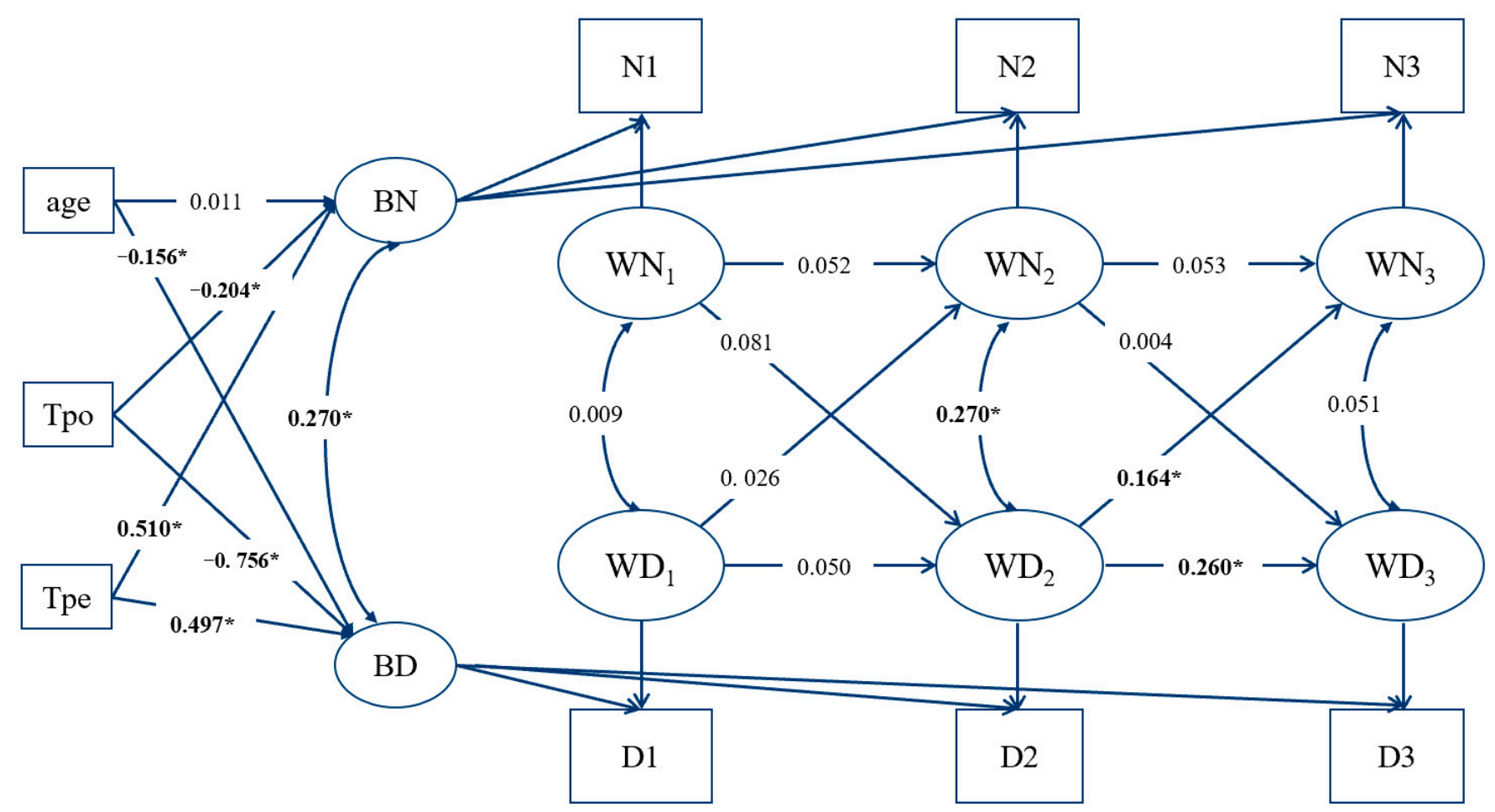

Figure 2. RI-CLPM of male group. Notes. BN = intercept of internet addiction, BD = intercept of depressive symptoms, $\mathrm{WN}=$ the within-person fluctuations of internet addiction, WD = the within-person fluctuations of depressive symptoms, N1-N3 are total scores of internet addiction at wave 1-wave 3, D1-D3 are total scores of depressive symptoms at wave 1 -wave $3 ;{ }^{*} p<0.05$.

Among the male group, the coefficients for depressive symptoms at $\mathrm{T}_{2}$ (WD2) to IA at $\mathrm{T}_{3}$ (WN3) were significant $(\beta=0.164, p=0.018)$, indicating that depressive symptoms at $\mathrm{T}_{2}$ (WD2) predicted the increases in IA at $\mathrm{T}_{3}(\mathrm{WN} 3)$. Other cross-lagged coefficients were all non-significant.

Focusing on the effects of covariates (age and coping style) on random intercept of internet addiction and depressive symptoms, age did not significantly predict the random intercept of internet addiction, but significantly negatively predicted the random intercept of depressive symptoms $(\beta=-0.156, p<0.001)$, in other words, the older adolescents have lower baseline level of depression. Positive coping style significantly negatively predicted the random intercept of internet addiction and depression $(\beta=-0.204, p<0.001$; $\beta=-0.756, p<0.001)$. This suggests that individuals who are more inclined to use positive coping strategy have lower baseline levels of internet addiction and depressive symptoms. Negative coping styles significantly positively predicted baseline levels of internet addiction and depressive symptoms $(\beta=0.510, p<0.001 ; \beta=0.497, p<0.001)$. This suggests that individuals who are more inclined to use negative coping strategy tend to have higher baseline levels of internet addiction and depressive symptoms.

The RI-CLPM for female group showed acceptable model fits, model fitting index are shown in Table 5, model diagram is shown in Figure 3.

Table 5. Model fitting index for female group.

\begin{tabular}{cccccc}
\hline CFI & TLI & SRMR & RMSEA & $\chi^{2}$ & $p$ \\
\hline 0.98 & 0.95 & 0.05 & 0.06 & 54.46 & 0.00 \\
\hline
\end{tabular}




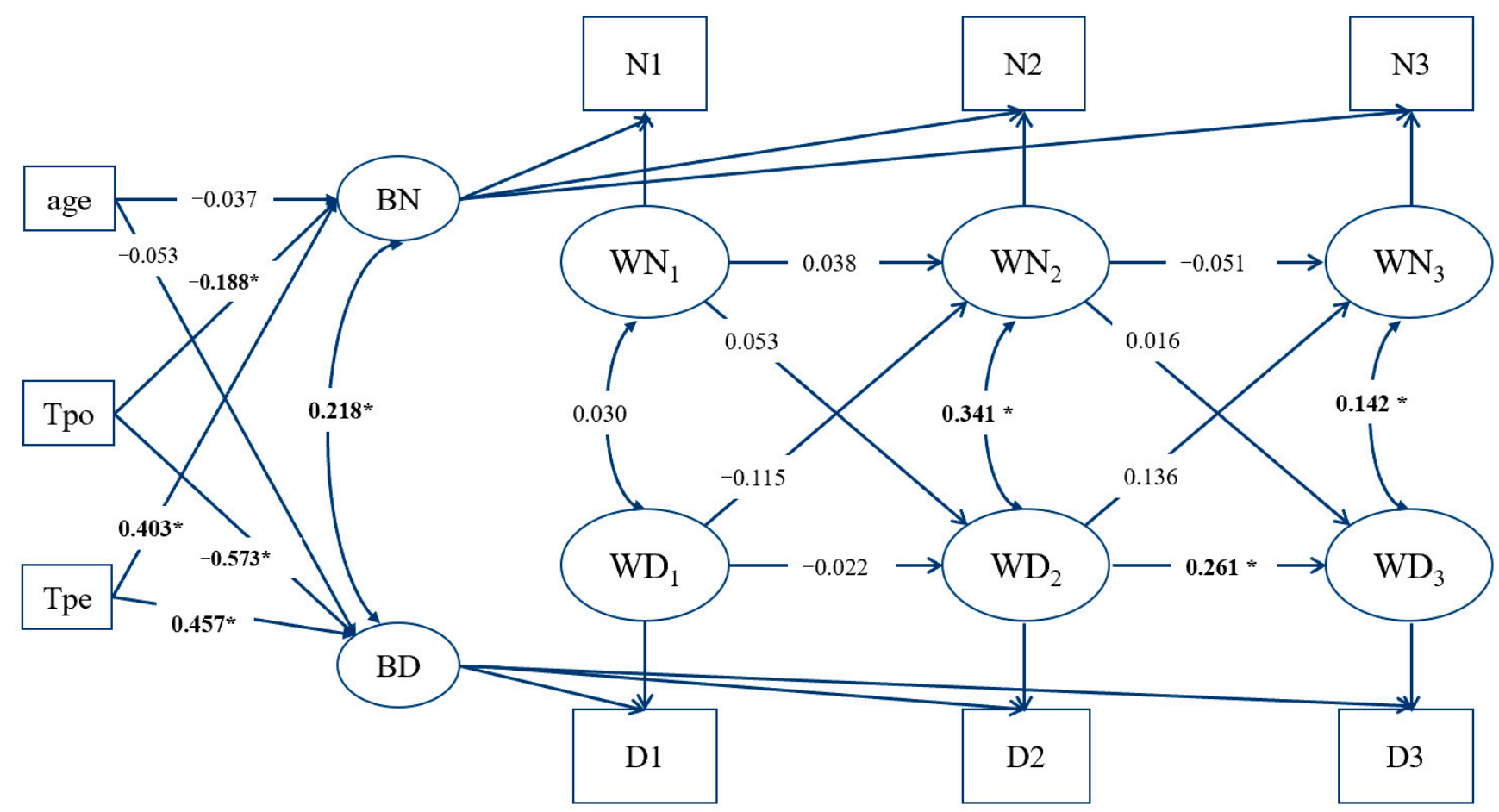

Figure 3. RI-CLPM of female group. Notes. BN = intercept of internet addiction, BD = intercept of depressive symptoms, $\mathrm{WN}=$ the within-person fluctuations of internet addiction, $\mathrm{WD}=$ the within-person fluctuations of depressive symptoms, N1-N3 are total scores of internet addiction at wave 1-wave 3, D1-D3 are total scores of depressive symptoms at wave 1 -wave $3 ;{ }^{*} p<0.05$.

As shown in Figure 3, among the female group, the cross-lagged coefficients from IA to depressive symptoms were not significant, while both the coefficients for depressive symptoms at $\mathrm{T}_{1}$ (WD1) to IA at $\mathrm{T}_{2}$ (WN2) $(\beta=-0.115, p=0.064)$ and the coefficients for depressive symptoms at $\mathrm{T}_{2}$ (WD2) to IA at $\mathrm{T}_{3}(\mathrm{WN} 3)(\beta=0.136, p=0.104)$ were marginally significant, which was inconsistent with the male group.

Focusing on the effects of covariates (age and coping style) on random intercept of internet addiction and depressive symptoms, age did not significantly predict the random intercept of internet addiction or depressive symptoms, and this also differs from the male group (in which age significantly predicts the random intercept of depression). Positive coping style significantly negatively predicted the random intercept of internet addiction and depressive symptoms $(\beta=-0.188, p<0.001 ; \beta=-0.573, p<0.001)$, suggesting that individuals who are more inclined to use positive coping strategy have lower baseline levels of internet addiction and depressive symptoms. Negative coping styles significantly positively predicted baseline levels of internet addiction and depressive symptoms ( $\beta=0.403, p<0.001 ; \beta=0.457, p<0.001)$, it suggests that individuals who are more inclined to use negative coping strategy tend to have higher baseline levels of internet addiction and depressive symptoms.

\section{Discussion}

The present research explored the longitudinal associations between internet addiction (IA) and depressive symptoms among adolescents. By utilizing the RI-CLPM, we disaggregated the within-person and between-person effects, and delineated the directionality of the association between two variables among total sample. Next, we established RI-CLPM in male and female group respectively to exam gender differences in the relationship between IA and depressive symptoms, and we also included covariates (age and coping strategies) to investigate their effects on random intercepts of internet addiction and depressive symptoms. 
Our research found that among total group, depressive symptoms at $T_{2}(W D 2)$ predicted the increases in IA at $\mathrm{T}_{3}(\mathrm{WN} 3)$, other cross-lagged effects were not significant. It is obvious that our research supports the mood enhancement hypothesis, while two previous similar studies supported the social displacement hypothesis. Zhou et al. studied the longitudinal relationship between problematic internet use (PIU) and mental health among 1579 college students in China using the RI-CLPM [38]. They found that PIU predicted the increases in mental health issues over time instead of the reverse. Differences in findings between our study and Zhou's study may be due to two reasons.

First of all, college students have easier access to the internet and generally experience few parental restrictions [38], they also have more free time surfing the internet, so they are more easily addicted to the internet and thus this leads to mental health problems; while middle school students have a heavy academic burden, little free time and strict restrictions on internet use at schools. Therefore, it is unlikely that internet addiction will lead to mental health problems. On the contrary, they are more likely to resort to maladaptive strategies such as internet addiction to seek relief and comfort under a poor condition of mental health (e.g., depression).

Secondly, college students have higher population mobility, they tend to go to university across provinces or cities, away from the original local social network, in the face of new physical and interpersonal environment, and they are more prone to maladjustment. Whether the internet is used as a tool for keeping up with physically distant friends in their home town or as a tool for making new friends online, it is not conducive to their adaptation to the new real-world interpersonal environment, thus leading to loneliness and depression. Middle-school students usually study in the place of domiciliary registration, and rarely go to other provinces or cities. As a result, they are constantly in local social networks and often do not need the network to support strong ties. In addition, under the strict discipline of schools and home, they have few opportunities to make friends online, so they are less likely to break away from their existing strong relationships because they are too addicted to the internet.

Kojima et al. conducted RI-CLPM analysis to explore the relationship between PIU and depressive symptoms among junior high-school students in Japan [39]. They found that PIU predicted depressive symptoms. Differences in findings between our study and their study may be due to different sample characteristics (size, age, nationality and region) and measurements (source of information, depression scales and internet addiction scales).

We also found gender differences in the relationship between internet addiction and depressive symptoms, the predictive effect of depression on internet addiction was more significant in the male group, so more importance should be attached to males. In addition, age in the male group significantly predicted the random intercept of depressive symptoms (i.e., the baseline level of the individual), while there was no such effect in the female group. Positive coping strategies had a significant negative predictive effect on the random intercept of internet addiction and depressive symptoms, while a negative coping style had a significant positive predictive effect on the random intercept of internet addiction and depressive symptoms, which was consistent in different gender groups. Therefore, we should pay attention to the cultivation of middle-school students' positive coping strategies and reduce their tendency of using negative coping styles.

According to the results of our research, adolescents who display a high level of depressive symptoms are in special need of attention, especially males. A screening program for depressive symptoms may provide the basis for effective intervention and prevention for internet addiction. At the same time, the cultivation of positive coping style will also help middle school students to relieve depression and reduce the baseline of internet addiction.

There are some limitations in the present research. Firstly, this study uses only selfreported questionnaires to collect data, although many previous studies on similar topics have done so, applying more diverse information collection methods will be better. Secondly, our participants are from only one city from southern China, this limited our findings' 
generalizability. It is necessary to recruit participants from different areas and cultural backgrounds. Thirdly, although we found the predictive effect of depressive symptoms on internet addiction, we cannot over-interpret our findings, because the prediction of depressive symptoms to internet addiction just occurs in $T_{2}$ to $T_{3}$. This may be for the following reason. The prevalence rate of depressive symptoms at $\mathrm{T}_{1}\left(\mathrm{~T}_{1}=42.15 \%\right)$ is much higher than the other two time points $\left(\mathrm{T}_{2}=31.53 \%, \mathrm{~T}_{3}=37.01 \%\right)$, and this indicates that the number of people with depressive symptoms at this time point is far more than that of the other two time points. It is plausible that adolescents with mild depressive symptoms may have better emotional regulation ability and can relieve their depressive moods in other, healthier ways, and so they are less likely to become addicted to the internet, while adolescents with severe depressive symptoms cannot deal with their depressive moods well, so they would tend to resort to internet addiction more. The prevalence rate of depressive symptoms at $T_{2}$ and $T_{3}$ is similar, indicating that people with severe depressive symptoms stayed. Therefore, the depressive symptoms at $T_{2}$ can obviously predict the internet addiction at $\mathrm{T}_{3}$. Therefore, it will be necessary for further studies to set up more time points and consider classifying subjects to see if there is a difference in the probability of internet addiction among people with different levels of depressive symptoms.

\section{Conclusions}

Ultilizing the RI-CLPM to disaggregate the within-person and between-person effects, our findings demonstrated that depressive symptoms predicted internet addiction but not vice versa at a within-person level. We also found gender differences in the relationship between internet addiction and depressive symptoms; the predictive effect of depressive symptoms on internet addiction was more significant in male group, so more importance should be attached to males. Positive coping strategies had a significant negative predictive effect on the random intercept of internet addiction and depressive symptoms, while negative coping style had a significant positive predictive effect on the random intercept of internet addiction and depressive symptoms. According to the results of our research, adolescents who display a high level of depressive symptoms are in special need of attention, especially males. Prevention and intervention strategies for reducing depressive symptoms may also help reduce internet addiction, and we should pay attention to the cultivation of middle-school students' positive coping strategies.

Author Contributions: Conceptualization, X.Y. and G.L.; methodology, X.Y.; software, X.Y.; writingoriginal draft preparation, X.Y. and G.L.; writing-review and editing, X.Y. and G.L. All authors have read and agreed to the published version of the manuscript.

Funding: This research was supported in part by Grant No. 18YJA190006 from the Ministry of Education Foundation of the People's Republic of China, Grant No. GD17CXL01 from the Philosophy and Social Science Foundation of Guangdong Province, and Grant No. 2021A1515012516 from the Natural Science Foundation of Guangdong Province.

Institutional Review Board Statement: Not applicable.

Informed Consent Statement: Informed consent was obtained from all subjects involved in the study.

Data Availability Statement: The data are not publicly available due to privacy restrictions.

Conflicts of Interest: The authors declare no conflict of interest.

\section{References}

1. China Internet Network Information Center (CNNIC). The 48th Statistical Report on the Development of Internet in China; CNNIC: Beijing, China, 2021; pp. 17-22. Available online: http://www.cnnic.net.cn/hlwfzyj/hlwxzbg/hlwtjbg/202109/t20210915_71543. htm (accessed on 10 October 2021). (In Chinese)

2. Young, K.S. Internet addiction: The emergence of a new clinical disorder. Cyber Psychol. Behav. 1998, 1, 237-244. [CrossRef]

3. China Internet Network Information Center (CNNIC). 2020 National Study Report on Internet Use by Minors; CNNIC: Beijing, China, 2020; pp. 1-9. Available online: http:/ /www.cnnic.net.cn/hlwfzyj/hlwxzbg/qsnbg/202107/t20210720_71505.htm (accessed on 10 October 2021). (In Chinese) 
4. Chou, C.; Hsiao, M.C. Internet addiction, usage, gratification, and pleasure experience: The taiwan college students' case. Comput. Educ. 2000, 35, 65-80. [CrossRef]

5. Yang, S.C.; Tung, C. Comparison of Internet addicts and non-addicts in taiwanese high school. Comput. Hum. Behav. 2007, 23, 79-96. [CrossRef]

6. Feng, Z.; Zhang, D. Epidemiological characteristics of depressive symptoms in middle school students. Chin. J. Behav. Med. Brain Sci. 2005, 14, 103-105.

7. Su, Z.; Kang, Y.; Li, J. Adolescent depression and its related influencing factors. Chin. J. Health Psychol. $2011,5,629-631$.

8. Al-gamal, E.; Alzayyat, A.; Ahmad, M.M. Prevalence of Internet addiction and its association with psychological distress and coping strategies among university students in Jordan. Perspect. Psychiatr. Care 2016, 52, 49-61. [CrossRef] [PubMed]

9. Compas, B.E.; Desjardins, L.; Vannatta, K.; Young-Saleme, T.; Rodriguez, E.M.; Dunn, M.; Bemis, H.; Snyder, S.; Gerhardt, C.A. Children and adolescents coping with cancer: Self- and parent reports of coping and anxiety/depression. Health Psychol. 2014, 33, 853-861. [CrossRef] [PubMed]

10. Kraut, R.; Patterson, M.; Lundmark, V.; Kiesler, S.; Mukophadhyay, T.; Scherlis, W. Internet paradox: A social technology that reduces social involvement and psychological well-being? Am. Psychol. 1998, 53, 1017-1031. [CrossRef]

11. Bryant, J.; Zillmann, D. Using Television to Alleviate Boredom and Stress: Selective Exposure as a Function of Induced Excitational States. J. Broadcasting 1984, 28, 1-20. [CrossRef]

12. Ko, C.; Yen, J.; Chen, C.; Yeh, Y.; Yen, C. Predictive values of psychiatric symptoms for Internet addiction in adolescents: A 2-year prospective study. Arch. Pediatrics Adolesc. Med. 2009, 163, 937-943. [CrossRef]

13. Davis, R.A. A cognitive-behavioral model of pathological Internet use. Comput. Hum. Behav. 2001, 17, 187-195. [CrossRef]

14. Seki, T.; Hamazaki, K.; Natori, T.; Inadera, H. Relationship between Internet addiction and depression among Japanese university students. J. Affect. Disord. 2019, 256, 668-672. [CrossRef] [PubMed]

15. Dalbudak, E.; Evren, C.; Aldemir, S.; Evren, B. The severity of Internet addiction risk and its relationship with the severity of borderline personality features, childhood traumas, dissociative experiences, depression and anxiety symptoms among Turkish University Students. Psychiatry Res. 2014, 219, 577-582. [CrossRef] [PubMed]

16. Yen, J.; Ko, C.; Yen, C.; Wu, H.; Yang, M. The comorbid psychiatric symptoms of Internet addiction: Attention deficit and hyperactivity disorder (ADHD), depression, social phobia, and hostility. J. Adolesc. Health 2007, 41, 93-98. [CrossRef] [PubMed]

17. Ostovar, S.; Allahyar, N.; Aminpoor, H.; Moafian, F.; Nor, M.B.M.; Griffiths, M.D. Internet addiction and its psychosocial risks (depression, anxiety, stress and loneliness) among Iranian adolescents and young adults: A structural equation model in a cross-sectional study. Int. J. Ment. Health Addict. 2016, 14, 257-267. [CrossRef]

18. Tian, Y.; Qin, N.; Cao, S.; Gao, F. Reciprocal associations between shyness, self-esteem, loneliness, depression and Internet addiction in chinese adolescents. Addict. Res. Theory 2020, 29, 98-110. [CrossRef]

19. Liang, L.; Zhou, D.; Yuan, C.; Shao, A.; Bian, Y. Gender differences in the relationship between Internet addiction and depression: A cross-lagged study in Chinese adolescents. Comput. Hum. Behav. 2016, 63, 463-470. [CrossRef]

20. Hamaker, E.L.; Kuiper, R.M.; Grasman, R.P.P.P. A critique of the cross-lagged panel model. Psychol. Methods 2015, 20, 102-116. [CrossRef]

21. Chakraborty, K.; Basu, D.; Kumar, K.G.V. Internet addiction: Consensus, controversies, and the way ahead. East Asian Arch Psychiatry 2010, 20, 123-132. [PubMed]

22. Weinstein, A.; Lejoyeux, M. Internet addiction or excessive Internet use. Am. J. Drug Alcohol Abus. 2010, 36, 277-283. [CrossRef]

23. Lu, Y.; Shek, D.T.L. Internet addiction in Hongkong adolescents: A three-year longitudinal study. J. Pediatric Adolesc. Gynecol. 2013, 26, S10-S17.

24. Avenevoli, S.; Swendsen, J.; He, J.; Burstein, M.; Merikangas, K.R. Major depression in the national comorbidity survey-adolescent supplement: Prevalence, correlates, and treatment. J. Am. Acad. Child Adolesc. Psychiatry 2015, 54, 37-44. [CrossRef] [PubMed]

25. Costello, E.J.; Copeland, W.; Angold, A. Trends in psychopathology across the adolescent years: What changes when children become adolescents, and when adolescents become adults? J. Child Psychol. Psychiatry 2011, 52, 1015-1025. [CrossRef] [PubMed]

26. Steinberg, L. (Ed.) Adolescence, 8th ed.; The McGrwa-Hill Companies: New York, NY, USA, 2007.

27. Hankin, B.L.; Abramson, L.Y.; Moffitt, T.E.; Silva, P.A.; McGee, R.; Angell, K.E. Development of depression from preadolescence to young adulthood: Emerging gender differences in a 10-year longitudinal study. J. Abnorm. Psychol. 1998, 107, 128-140. [CrossRef] [PubMed]

28. Lewis, A.J.; Kremer, P.; Douglas, K.; Toumborou, J.W.; Williams, J. Gender differences in adolescent depression: Differential female susceptibility to stressors affecting family functioning. Aust. J. Psychol. 2015, 67, 131-139. [CrossRef]

29. Billings, A.G.; Moos, R.H. The role of coping responses and social resources in attenuating the stress of life events. J. Behav. Med. 1981, 4, 139-157. [CrossRef]

30. Nedim-Bal, P.; Metan, H. The effect of computer addiction management psycho training program on 9th grade students. Abant İzet Baysal Üniversitesi Ĕ̆itim Fakültesi Derg. 2016, 16, 62-74.

31. Whang, L.S.; Lee, S.; Chang, G. Internet over-users' psychological profiles: A behavior sampling analysis on Internet addiction. Cyber Psychol. Behav. 2003, 6, 143-150. [CrossRef]

32. McMahon, E.M.; Corcoran, P.; McAuliffe, C.; Keeley, H.; Perry, I.J.; Arensman, E. Mediating effects of coping style on associations between mental health factors and self-harm among adolescents. Crisis J. Crisis Interv. Suicide Prev. 2013, 34, 242-250. [CrossRef] 
33. Valiente, C.; Lemery-Chalfant, K.; Swanson, J. Children's responses to daily social stressors: Relations with parenting, children's effortful control, and adjustment. J. Child Psychol. Psychiatry 2009, 50, 707-717. [CrossRef]

34. Budge, S.L.; Adelson, J.L.; Howard, K.A.S. Anxiety and depression in transgender individuals: The roles of transition status, loss, social support, and coping. J. Consult. Clin. Psychol. 2013, 81, 545-557. [CrossRef] [PubMed]

35. Hogendoorn, S.M.; Prins, P.J.M.; Boer, F.; Vervoort, L.; Wolters, L.H.; Moorlag, H.; Nauta, M.H.; Garst, H.; Hartman, C.A.; de Haan, E. Mediators of cognitive behavioral therapy for anxiety-disordered children and adolescents: Cognition, perceived control, and coping. J. Clin. Child Adolesc. Psychol. 2014, 43, 486-500. [CrossRef]

36. Zung, W.W. A self-rating depression scale. Arch. Gen. Psychiatry 1965, 12, 63-70. [CrossRef]

37. Kline, R.B. Principles and Practice of Structural Equation Modeling, 3rd ed.; Guilford Press: New York, NY, USA, 2015.

38. Zhou, N.; Cao, H.; Liu, F.; Wu, L.; Liang, Y.; Xu, J.; Meng, H.; Zang, N.; Hao, R.; An, Y.; et al. A four-wave, cross-lagged model of problematic internet use and mental health among Chinese college students: Disaggregation of within-person and between-person effects. Dev. Psychology 2020, 56, 1009-1021. [CrossRef] [PubMed]

39. Kojima, R.; Shinohara, R.; Akiyama, Y.; Yokomichi, H.; Yamagata, Z. Temporal directional relationship between problematic Internet use and depressive symptoms among Japanese adolescents: A random intercept, cross-lagged panel model. Addict. Behav. 2021, 120, 6. [CrossRef] [PubMed] 